\title{
THEORETICAL INVESTIGATION OF ELECTRONIC STRUCTURE AND BONDING IN MOLYB- DENUM FACE-BRIDGED OCTAHEDRAL CLUSTERS WITH ח-DONOR LIGANDS
}

\author{
NEBBACHE N..$^{1,2 *}$, BELHOCINE Y. ${ }^{3}$, BENCHARIF M. ${ }^{3}$ AND MEGHEZZI A. ${ }^{1}$ \\ 1 Laboratoire de chimie appliquée, Université de Biskra, BP 145, R.P. 07000 Biskra, Algeria \\ 2Sciences Chimiques de Rennes, UMR 6226 CNRS - Université de Rennes1 - Ecole nationale Supérieure de Chimie de Rennes, Avenue du \\ Général Leclerc, CS 50837, 35708 Rennes Cedex, France \\ ${ }^{3}$ Faculté des Sciences Exactes, Département de Chimie, Université Mentouri de Constantine, 25000 Constantine, Algeria \\ *Corresponding Author: Email- nadia_nebbache@yahoo.fr
}

Received: May 26, 2012; Accepted: June 18, 2012

\begin{abstract}
Extended Hückel Molecular Orbital (EHMO) calculations were carried out on octahedral transition metal clusters with general formula $\left[\mathrm{M}_{6} \mathrm{X}_{8} \mathrm{Y}_{6}{ }^{\mathrm{a}}\right.$ ] ( $\mathrm{M}=$ Molybdenum; $\mathrm{X}$ and $\mathrm{Y}=\pi$-Donor Ligands) in order to rationalize their electronic structure. In these species the optimal metallic electron (ME) count is of 24 but for many clusters experimentally synthesized, the ME count can vary from 20 to 48 without dramatically altering the architecture of the octahedral cluster. Herein are reported the geometrical parameters and electronic properties, of a series of clusters with 20 to 24 valence electrons per cluster. The calculated characteristics for all the considered structures are in excellent agreement with the experimental ones and requires to learn more about the relationships that exist between their structural arrangement and electronic properties especially the number of electrons available for metal-metal bonding in $\mathrm{M}_{6}$ octahedral clusters.
\end{abstract}

Keywords- Cluster Compounds, Molybdenum, Electron counting, Extended Hückel Molecular Orbital (EHMO) calculations, Electronic Structure, Frontier orbitals.

Citation: Nebbache N., et al. (2012) Theoretical Investigation of Electronic Structure and Bonding in Molybdenum Face-Bridged Octahedral Clusters with П-Donor Ligands. International Journal of Chemical Research, ISSN: 0975-3699 \& E-ISSN: 0975-9131, Volume 4, Issue 2, pp. $-130-133$

Copyright: Copyright@2012 Nebbache N., et al. This is an open-access article distributed under the terms of the Creative Commons Attribution License, which permits unrestricted use, distribution, and reproduction in any medium, provided the original author and source are credited.

\section{Introduction}

Transition metal clusters exhibit a wide range of nuclearity with intriguing structural diversity [1-6]. Considerable attention attracted to the cluster compounds is caused by their remarkable properties and great technological application in many fields [7-10]. Systematic efforts aimed at understanding the electronic structure and bonding of these compounds have been initiated by several research groups by developing topological electron counting theories [3, 11-13].

The first Octahedral transition metal clusters with general formula $\left[M_{6} L_{8}{ }^{i} L_{6}{ }^{a}\right]$ ( $i=$ inner, $a=$ apical, relatively to Shäfer and Schnering notation) [14], have been a subject of extensive investigations because of their very interesting properties [15-21]. Such compounds are built up from $M_{6} L_{14}$ units ( $M=$ transition metal, $L=$ halogen, chalcogen) in which the $M_{6}$ cluster is face-capped by eight inner ligands $\left(L^{i}\right)$ and six apical ligands $\left(L^{a}\right)$ lie in terminal positions (see Fig. 1).

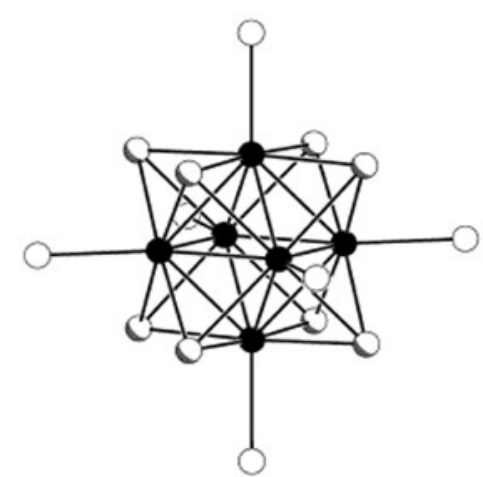

Fig. 1- Structural arrangement of $\left[M_{6} L^{i} L^{2}{ }_{6}\right]$ clusters.

The $\left[\mathrm{M}_{6} \mathrm{~L}_{8} \mathrm{~L}_{6}{ }^{\mathrm{a}}\right]$ units are the basic building blocks in the early transition metal particularly in the molybdenum, tungsten and rhenium octahedral cluster chemistry [22-28]. Several theoretical studies of 
chemical bonding in these clusters indicates that metallic electrons occupy a set of 12 frontier orbitals, spanning $a_{1 g}, t_{1 u}, t_{2 g}, t_{2 u}$ and $e_{g}$ in the ideal $O_{h}$ symmetry. For clusters with halide ligands, the full occupation of these orbitals satisfy the closed shell requirement and leads to an optimal electron count equal to 24; whereas the ME count can vary from 20 to 48 , owing to the topological properties of the frontier orbitals and to the metal and ligands nature (see Table 1 for a partial list) [29-52]. In this contribution, our aim is to analyse the electronic structure of molybdenum face-bridged octahedral clusters with $\pi$-Donor ligands with 20 to $24 \mathrm{ME}$ count, in order to explain the relationships that exist between the number of electrons available for metal-metal bonding and the structural arrangement of these cluster compounds.

\section{Materials and Methods}

All the calculations reported here were performed according to the extended Hückel theory (EHT) approach [49-51] utilizing C.A.C.A.O. (Computer Aided Composition of Atomic Orbitals) program [52] with using the weighted Hij formula. No spin-orbit effects were introduced. The exponents $(x)$ and the valence shell ionization potentials ( $\mathrm{Hij}$ in $\mathrm{eV}$ ) were respectively shown in Table 2. The EHMO method had been applied for a single regular octahedron obtained from the real bond lengths and angles found from the X-ray diffraction.

\section{Results and Discussion \\ Qualitative Approach}

For $\left[M_{6} L_{i}{ }^{i}{ }_{6} a_{6}\right]$ unit in octahedral cluster compounds, it was shown that the optimal metallic electron (ME) count, i.e. electrons available for metal-metal bonding, is equal to 24 . Owing to the topological properties of the HOMO ( $e_{g}$ in $\mathrm{O}_{h}$ symmetry), the ME count can vary from 20 to 24 for early transition metals and from 24 to 48 for late transition metals without significantly altering the architecture of the $\mathrm{M}_{6} \mathrm{~L}_{8} \mathrm{~L}_{6} \mathrm{a}_{6}$ cluster (Table 1).

Table 1- Examples of transition metal octahedral clusters with $\pi$ -

\begin{tabular}{|c|c|c|c|}
\hline Cluster & MEa & $\left.\mathrm{d}_{M-M}(\AA) \mathrm{A}\right)^{b}$ & Reference \\
\hline$\left[\mathrm{Mo}_{6} \mathrm{Si}_{8}\left(\mathrm{PEt}_{3}\right)^{\mathrm{a}_{6}}\right]$ & 20 & 2.66 & 29 \\
\hline$\left[\mathrm{Mo}_{6} \mathrm{Se}_{8} \mathrm{i}_{8}\left(\mathrm{PEt}_{3}\right)_{6}{ }_{6}\right]$ & 20 & 2.7 & 29 \\
\hline$\left.\left[\mathrm{W}_{6} \mathrm{Si}_{8}\left(\mathrm{PEt}_{3}\right)_{6}\right)_{6}\right]$ & 20 & 2.68 & 30 \\
\hline$\left[\mathrm{Mo}_{6} \mathrm{Si}_{8}\left(\mathrm{PEt}_{3}\right)^{\mathrm{a}_{6}}\right]^{-}$ & 21 & 2.67 & 29 \\
\hline$\left[\mathrm{Mo}_{6} \mathrm{Se}_{8}\left(\mathrm{PEt}_{3}\right)^{\mathrm{a}_{6}}\right]^{-}$ & 21 & 2.71 & 29 \\
\hline$\left[\mathrm{Nb}_{6} \mathrm{l}_{8}\left(\mathrm{NH}_{2} \mathrm{CH}_{3}\right)_{6} \mathrm{a}_{6}\right]$ & 22 & 2.75 & 31 \\
\hline$\left[\mathrm{W}_{6} \mathrm{Cll}_{8} \mathrm{Cla}_{6}\right]^{-}$ & 23 & 2.63 & 32 \\
\hline$\left[\mathrm{W}_{6} \mathrm{Cl}_{8} \mathrm{Cla}_{6}\right]^{2-}$ & 24 & 2.61 & 33 \\
\hline$\left[\mathrm{Mo}_{6} \mathrm{Cl}_{8} \mathrm{Cla}_{6}\right]^{2-}$ & 24 & 2.62 & 34 \\
\hline$\left[\mathrm{Mo}_{6} \mathrm{Br}_{8} \mathrm{Bra}_{6}\right]^{2-}$ & 24 & 2.63 & 35 \\
\hline$\left[\mathrm{Mo}_{6} \mathrm{Cli}_{8} \mathrm{Br}_{6}\right]^{2-}$ & 24 & 2.62 & 36 \\
\hline$\left[\mathrm{Mo}_{6} \mathrm{Cl}_{7} \mathrm{SiCla}_{6}\right]^{3-}$ & 24 & 2.62 & 37 \\
\hline$\left[\mathrm{Re}_{6} \mathrm{Se}_{6} \mathrm{Cli}_{2} \mathrm{Cla}_{6}\right]^{2-}$ & 24 & 2.61 & 38 \\
\hline$\left[\mathrm{Re}_{6} \mathrm{Se}_{5} \mathrm{Cll}_{3} \mathrm{Cla}_{6}\right]^{-}$ & 24 & 2.61 & 38 \\
\hline$\left[\mathrm{Re}_{6} \mathrm{Se}_{4} \mathrm{Cl}_{4} \mathrm{Cla}_{6}\right]$ & 24 & 2.61 & 39 \\
\hline$\left[\mathrm{Fe}_{6} \mathrm{Si}_{8}\left(\mathrm{PEt}_{3}\right)^{\mathrm{a}_{6}}\right]^{2+}$ & 30 & 2.62 & 40 \\
\hline$\left[\mathrm{Fe}_{6} \mathrm{Si}_{8}\left(\mathrm{PEt}_{3}\right)_{6}{ }_{6}\right]^{+}$ & 31 & 2.64 & 41 \\
\hline$\left[\mathrm{Fe}_{6} \mathrm{Te}_{8} \mathrm{i}_{8}\left(\mathrm{PMe}_{3}\right)_{6}^{\mathrm{a}_{6}}\right]$ & 32 & 2.9 & 42 \\
\hline$\left.\left[\mathrm{CO}_{6} \mathrm{Te}_{8}\left(\mathrm{PEt}_{3}\right)_{6}\right]_{6}\right]^{2+}$ & 36 & 3.14 & 43 \\
\hline$\left.\left[\mathrm{CO}_{6} \mathrm{Se}_{8}\left(\mathrm{PPh}_{3}\right)_{6}\right]\right]^{+}$ & 37 & 2.9 & 44 \\
\hline$\left[\mathrm{CO}_{6} \mathrm{Si}_{8}\left(\mathrm{PEt}_{3}\right)_{6}{ }_{6}\right]^{+}$ & 37 & 2.79 & 45 \\
\hline$\left[\mathrm{CO}_{6} \mathrm{Te}_{8}\left(\mathrm{PEt}_{3}\right) \mathrm{a}_{6}\right]$ & 38 & 3.23 & 46 \\
\hline$\left[\mathrm{Co}_{6} \mathrm{Se}_{8}\left(\mathrm{PPh}_{3}\right)_{6}{ }^{\mathrm{a}_{6}}\right]$ & 38 & 3.01 & 47 \\
\hline$\left.\left[\mathrm{Pd}_{6} \mathrm{Tei}_{8}\left(\mathrm{PEt}_{3}\right)_{6}\right]_{6}\right]^{4-}$ & 48 & 3.03 & 48 \\
\hline
\end{tabular}

Table 2- Parameters used in extended Hückel molecular orbital calculations

\begin{tabular}{|lllllll|} 
Atom & Orbital & $\mathrm{H}_{\mathrm{ij}}(\mathrm{eV})$ & $\xi_{1}$ & $\xi_{2}$ & $\mathrm{C}_{1}$ & $\mathrm{C}_{2}$ \\
\hline $\mathrm{H}$ & $1 \mathrm{~s}$ & -13.60 & 1.30 & & & \\
$\mathrm{P}$ & $3 \mathrm{~s}$ & -18.60 & 1.60 & & & \\
& $3 \mathrm{p}$ & -14.00 & 1.60 & & & \\
$\mathrm{~S}$ & $3 \mathrm{~s}$ & -20.00 & 1.81 & & & \\
& $3 \mathrm{p}$ & -13.30 & 1.81 & & & \\
$\mathrm{Cl}$ & $3 \mathrm{~s}$ & -26.30 & 2.18 & & & \\
& $3 \mathrm{p}$ & -14.20 & 1.73 & & & \\
$\mathrm{Br}$ & $4 \mathrm{~s}$ & -25.00 & 2.64 & & & \\
& $4 \mathrm{p}$ & -31.10 & 2.26 & & & \\
$\mathrm{I}$ & $5 \mathrm{~s}$ & -17.80 & 2.68 & & & \\
& $5 \mathrm{p}$ & -12.00 & 2.32 & & & \\
$\mathrm{Mo}$ & $5 \mathrm{~s}$ & -8.34 & 1.96 & & & \\
& $5 \mathrm{p}$ & -5.24 & 1.92 & & & \\
& $4 \mathrm{~d}$ & -10.5 & 4.54 & 1.90 & 0.6097 & 0.6097 \\
\hline
\end{tabular}

Qualitatively, the structure of $\left[M_{6} L_{8} L_{6}{ }^{a}\right]$ can be described as consisting of six ML 5 fragments where each metal centre have 5 metal -ligand $s$ bonds with a square pyramidal arrangement. The frontier orbitals denoted FO are one s-type hybrid and the $t_{2 g}$ set (two $d(p)$ and one d (d)) [53]. In the $O_{h}$ symmetry of the cluster, the orbital interaction among the six s hybrid frontier orbitals gives rise to one strongly bonding orbital $a_{1 g}$ and five antibonding molecular orbitals $\left(t_{14}+e_{g}\right)$. The result of the interaction among the six sets of " $t_{2 g}$ " frontier orbitals gives for the $12 \mathrm{~d}(p)$ orbitals, six bonding MO's ( $t_{1 u}$ $+t_{2 g}$ ) and six antibonding $\left(t_{2 u}+t_{19}\right)$; and the interaction of the six FOs $\mathrm{d}(\mathrm{d})$ gives one non-bonding orbital ( $\mathrm{a}_{2 \mathrm{u}}$ ) and five antibonding $\left(e_{u}+t_{2 g}\right)$. Due to the existence of MO's having the same symmetry, there is a second order mixing which leads to two widely separated sets: 12 bonding and 12 antibonding MO's. Therefore, for the complete occupation of all bonding MO's, the optimal count for these compounds is of $24 \mathrm{ME}$ (Fig. 2).

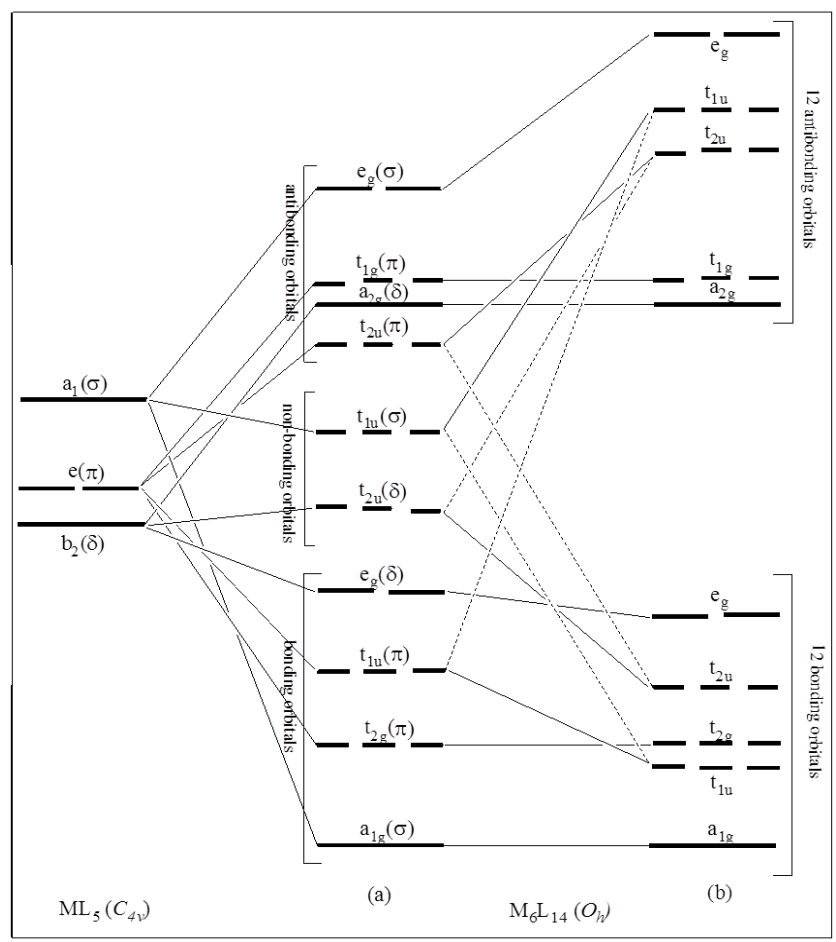

Fig. 2- Qualitative molecular orbital interaction diagram for [M6Li8La6] clusters 


\section{Molecular Orbital Calculations}

EHMO calculations were first carried out on $24 \mathrm{ME}$ then on $20 \mathrm{ME}$ count cluster models respectively $\left[\left(\mathrm{Mo}_{6} \mathrm{Cli}_{8}\right) \mathrm{La}_{6}\right]^{2-}(\mathrm{M}=\mathrm{Mo}, \mathrm{L}=\mathrm{Cl}$, $\mathrm{Br}$, or I) and $\left[\mathrm{Mo}_{6} \mathrm{Si}_{8}\left(\mathrm{PH}_{3}\right)_{6}{ }_{6}\right]$. The crystal structures of isomorphous complexes $\mathrm{Cs}_{2}\left[\left(\mathrm{M}_{6} \mathrm{Cl}_{8}\right) \mathrm{L}_{6}\right](\mathrm{M}=\mathrm{Mo}$ or $\mathrm{W} ; \mathrm{L}=\mathrm{Cl}, \mathrm{Br}$, or I), have been determined from single-crystal $X$-ray diffraction [36]. The mean metal-metal distances are Mo-Mo 2.615 $\pm 0.006 \AA$. Calculation were performed on $\left[\left(\mathrm{Mo}_{6} \mathrm{Cl}_{8}\right) \mathrm{La}_{6}\right]^{2-}$ using idealised geometry in $\mathrm{O}_{h}$ symmetry. The molecular orbital diagram obtained schematically illustrated in Fig. 3 complies with the qualitative one (Fig. 2).

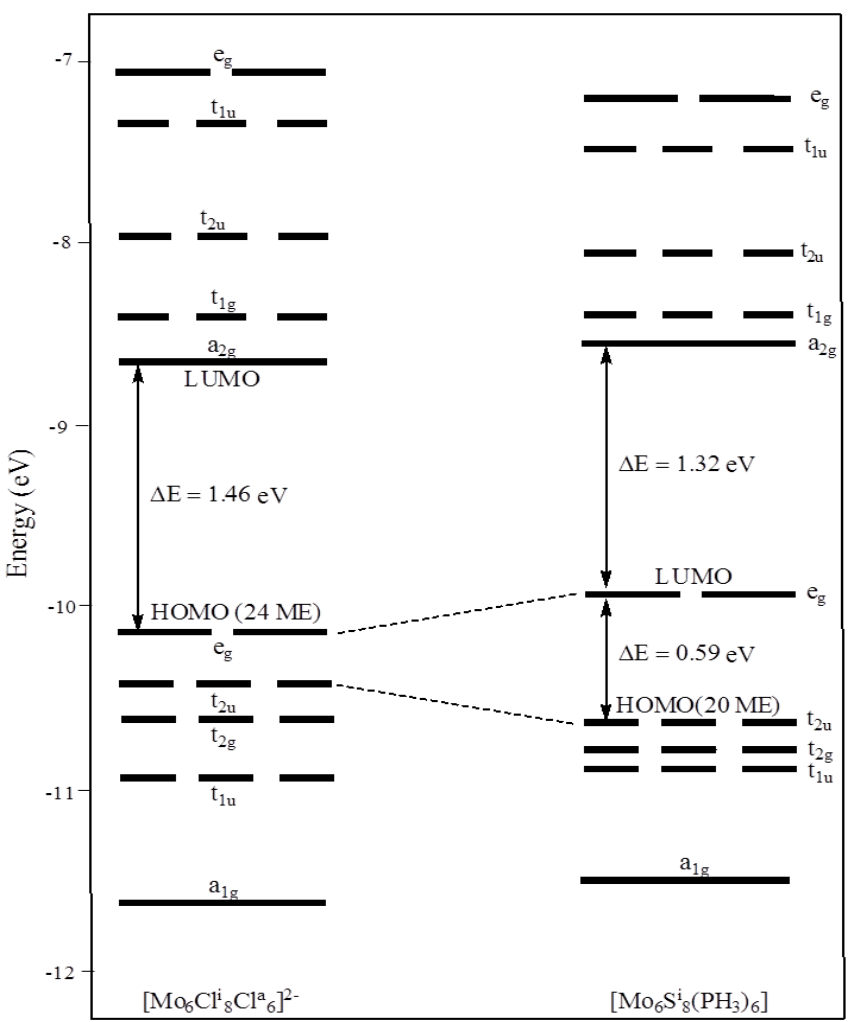

Fig. 3- Molecular orbital diagram of $\left[\mathrm{Mo}_{6} \mathrm{Cl}_{8} \mathrm{Cla}_{6}\right]^{2-}$ and $\left[\mathrm{Mo}_{6} \mathrm{Si}_{8}\right.$ $\left(\mathrm{PEt}_{3}\right)_{6} \mathrm{a}_{6}$.

For all apical ligands $(\mathrm{L}=\mathrm{Cl}, \mathrm{Br}$ or $\mathrm{I})$ the molecular orbital diagram exhibit a sizable gap of $1.46 \mathrm{eV}$ separating the highest occupied molecular orbital (HOMO) $e_{g}$, from the lowest unoccupied molecular orbital (LUMO) $a_{2 g}$, leading to diamagnetic electron configuration and ensuring the stability of the cluster for 24 EM count. Formally, each metal atom is in the +2 oxidation state; however the analysis of results shows that the chemical bond is partially covalent with significant delocalization throughout the system.

Tables 3 and 4 show respectively the atomic net charges and the overlap populations. It is clear that our compound possesses 24 metal electrons, without localized bonds (2 electron / 2 centres). The inner ligands are slightly positive but apical ones are largely negative which indicate that $M-L i$ bonds are essentially covalent in nature, whereas $\mathrm{M}-\mathrm{L}$ a bonds are rather ionic in character.

For $\left[\mathrm{Mo}_{6} \mathrm{Si}_{8}\left(\mathrm{PH}_{3}\right)^{\mathrm{a}} 6\right.$ ] cluster, the molecular orbital diagram (Fig. 3) show that among bonding levels only ten (10) are occupied. The HOMO-LUMO energy gap calculated is of $0.596 \mathrm{eV}$, it is low in comparison with the energy gap between the LUMO $e_{g}$ and the level $a_{1 \mathrm{~g}}$ directly above which is of $1.32 \mathrm{eV}$. The LUMO $e_{g}$ is con- stituted by $75 \%$ of Mo d type orbitals and $25 \%$ of $S$ (s, p) type orbitals with Mo-Mo slightly bonding character and slightly Mo-S antibonding character. The filling of the LUMO, in this case, corresponds to the hypothetical charged species $\left[\mathrm{Mo}_{6} \mathrm{Si}_{8}\left(\mathrm{PH}_{3}\right){ }_{6}\right]^{4}$ which leads to the optimal electron count of $24 \mathrm{ME}$. Based on these results, clusters with intermediate electron counts from 20 to 24 electrons should be favoured [29-31]. We note that for 21, 22 and 23 EM species, we have a partial occupation of the LUMO (eg) which is doubly degenerate leading to a distortion of the octahedral core by Jahn-Teller effect and these clusters exhibit paramagnetic properties.

The overlap population computed for $\left[\mathrm{Mo}_{6} \mathrm{Si}_{8}\left(\mathrm{PH}_{3}\right)_{6} \mathrm{a}_{6}\right]$ are of 0.235 for M-M bonds and of 0.425 for M-Li. Compared to $24 \mathrm{ME}$ species, the same relatively octahedral unit is observed with some significant lengthening of Mo-Mo distances and some shortening of the M-Li separations (see Table1).

Table 3- Computed Mulliken Net Charges in selected $\left[\mathrm{Mo}_{6} \mathrm{Cli}_{8} \mathrm{~L}_{6}{ }_{6}\right]^{-2}$ models

\begin{tabular}{llll} 
& \multicolumn{3}{c}{ Net Charge } \\
Cluster & Mo & $\mathrm{Cl}$ & $\mathrm{X}^{\mathrm{a}}$ \\
{$\left[\mathrm{Mo}_{6} \mathrm{Cl}_{8} \mathrm{Cla}_{6}\right]^{-2}$} & 0.249 & 0.055 & -0.656 \\
{$\left[\mathrm{Mo}_{6} \mathrm{Cl}_{8} \mathrm{Bra}_{6}\right]^{-2}$} & 0.212 & 0.058 & -0.623 \\
{$\left[\mathrm{Mo}_{6} \mathrm{Cl}_{8} \mathrm{a}_{6}\right]^{-2}$} & 0.161 & 0.052 & -0.463 \\
\hline
\end{tabular}

Table 4- Computed overlap populations in selected $\left[\mathrm{Mo}_{6} \mathrm{Cl}_{8} \mathrm{~L}^{\mathrm{a}} 6\right]^{-2}$ models

\begin{tabular}{llll} 
& Mo-Mo & Mo-Cl & Mo-LT \\
{$\left[\mathrm{Mo}_{6} \mathrm{Cl}_{8} \mathrm{Cla}_{6}\right]^{-2}$} & 0.238 & 0.369 & 0.358 \\
{$\left[\mathrm{Mo}_{6} \mathrm{Cl}_{8} \mathrm{Br}_{6}\right]^{-2}$} & 0.237 & 0.366 & 0.375 \\
{$\left[\left.\mathrm{Mo}_{6} \mathrm{Cl}_{8}\right|_{6} \mathrm{a}_{6}\right]^{-2}$} & 0.237 & 0.364 & 0.503 \\
\hline
\end{tabular}

\section{Conclusion}

The molecular orbital calculations described above have shown that, for the molybdenum octahedral face bridged clusters $\left[\mathrm{M}_{6} \mathrm{~L}_{8} \mathrm{~L}_{6} \mathrm{a}\right]$ with $\mathrm{m}$-Donor ligands, the complete occupation of the Metal-Metal bonding MOs fulfills the closed-shell requirement with $24 \mathrm{ME}$ count. According to MO diagrams, the HOMO $\mathrm{e}_{\mathrm{g}}$ level is lying in the middle of large energy gap between the bonding $t_{2 u}$ and antibonding $a_{2 g}$ levels and the energy gap is controlled by the nature of apical ligands $L^{a}$ and their contribution in molecular orbitals which is in agreement with the existence of two favoured closed-shell electron counts of 20 and 24 , as well as with intermediate one of 21,22 and 23 . Finally, we note that the calculations performed confirm all qualitative and $\mathrm{MO}$ analysis reported in literature and are in full agreement with experimental data.

\section{Acknowledgements}

This work has been financially supported by the Algerian Ministry of Higher Education and Scientific research (MESRS-ALGERIA) trough intergovernmental program grant (Bourse AlgéroFrançaise), it is gratefully acknowledged. The authors wish also to thank Prof. Jean-François Halet and Prof Jean-Yves Saillard, Rennes 1 University for useful and enlightening discussions on the theoretical calculations.

\section{References}

[1] Mingos D. M. P. and Wales D. J. (1990) Introduction to Cluster 
Chemistry, Prentice-Hall, London.

[2] Wade K. (1980) Transition Metal Clusters, B. F. G Johnson (Eds.), John Wiley \& Sons, Chichester, England.

[3] Fehlner T.P., Halet J.F. and Saillard J.Y. (2007) Molecular Clusters. A Bridge to Solid state Chemistry, Cambridge University Press, Cambridge.

[4] Simon A. (1994) Clusters and Colloids: From Theory to Applications, G. Schmid (Ed.), VCH, Weinheim,

[5] Cotton F.A., Wilkinson G. and Gaus P.L. (1995) Basic inorganic chemistry, Ed. John Wiley \& Sons, Chichester, England,

[6] Kepert D.L. (1972) The Early Transition Metals, Academic Press, New-York.

[7] Braunstein P., Oro L.A. and Raithby P.R. (1999) Metal clusters in chemistry, Molecular metal clusters, Weinheim: WileyVCH, 1 .

[8] Ghosh R.N., Askeland P.A., Kramer S. and Loloee R. (2011) Appl. Phys. Lett., 98(22), 221103- 221105.

[9] Fackler J. P. (1990) Metal-Metal Bonds and Clusters in Chemistry and Catalysis, Texas A\&M University Press, USA.

[10]Shriver D.F., Kaesz H.D. and Adams R.D. (1990) The Chemistry of Metal Cluster Complexes, VCH, New York,.

[11]Simon A. (1991) in: Handbook on physics and chemistry of rare earths, Karl Gschneidner Jr., Eyring L. (Eds.), Elsevier Science Publishers B.V., New York, 15, 195.

[12]Wade K. (1971) J. Chem. Soc. D., 15, 792-793.

[13]Wade K. (1971) Electron deficient compounds, Nelson: London.

[14]Schäfer H. and von Schnering H.G. (1964) Angew. Chem. 76 (20), 833-849.

[15]Chevrel R. and Sergent M. (1982) Topics in Current Physics, Superconductivity in Ternary Compounds, Springer, Berlin.

[16]Gray H. B. and Maverick A. W. (1981) Science; 214(4526), 1201-1205

[17]Maverick A.W. and Gray H.B. (1981) J. Am. Chem. Soc. 103 (5), 1298-1300.

[18]Maverick A.W., Najdzionek J.S., Mackenzle D., Nocera D.G. and Gray H.B. (1983) J. Am. Chem. Soc., 105(7), 1878-1882.

[19]Preetz W., Harder K., von Shering H.G., Kliche G. and Peters K. (1992) J. Alloys Compd. 183(5), 413-429.

[20]Zietlow T.C., Hopkins M.D. and Gray H.B. (1985) J. Solid State Chem. 57(1), 112-119.

[21]Arratia-Pérez R. and Hernández-Acevedo L. (1999) J. Chem. Phys. 111(1), 168-172.

[22]Ramirez-Tagle R. and Arratia-Pérez R. (2009) Chem. Phys. Lett. 475(4), 232-234.

[23]Ramírez-Tagle R., Alvarado-Soto L., Hernández-Acevedo L. and Arratia-Pérez R. (2010) J. Chil. Chem. Soc. 55(1), 39-43.

[24] Ghosh R.N., Askeland P.A., Kramer S. and Loloee R. (2011) Appl. Phys. Lett., 98(22), 221103-221105.

[25]Gabriel J.P., Boubekeur K., Uriel S. and Batail P. (2001) Chem. Rev., 101(7), 2037-2066.

[26]Hughbanks T. and Hoffmann R. (1983) J. Am. Chem. Soc. 105(5), 1150-1162.

[27]Hughbanks T. (1989) Prog. Solid. State Chem. 19(4), 329373.

[28]Kim Y., Fedorov V.E. and Kim S.J. (2009) J. Mater. Chem. 19 (39), 7178-7190.

[29]Saito T., Yamamoto N., Nagase T., Tsuboi T., Koyabashi K.,
Yamagata T., Imoto H. and Unoural K. (1990) Inorg. Chem., 29(4), 764-770.

[30]Saito T., Yoshikawa A., Yamagata T., Imoto H. and Unoura K. (1989) Inorg. Chem. 28(18), 3588-3592.

[31]Stollmaier F. and Simon A. (1985) Inorg. Chem., 24(2),168171.

[32]Mussell R.D. and Nocera D.G. (1990) Inorg. Chem., 29(19), 3711-3717.

[33]Zheng Y.Q., Peters K., Grin Y. and von Schnering H.G. (1998) Z. Anorg. Allg. Chem. 624, 506-512.

[34]Adams R.D., Chen G. and Huang J. (1993) J. Clust. Sci. 4(3), 271-277.

[35]Flemström A., Hirsch T.K., Eriksson L. and Lidin S. (2004) Solid State Sciences 6(6), 509-517.

[36]Healy P.C., Kepert D.L., Taylor D. and White A.H. (1973) J. Chem. Soc. Dalton Trans. 6, 646-650.

[37]Petrov P.A., Naumov D.Y. and Konchenko S.N. (2012) Acta Cryst. E., 68(1), 333-334.

[38]Perrin A. and Sergent M. (1988) New J. Chem. 12(6), 337356.

[39]Leduc L., Perrin A., Sergent M., Le Traon F., Pillet J. C. and Le Traon (1985) A. Mater. Lett. 3(5), 209-215.

[40]Bencini A., Ghilardi C.A., Midollini S., Orlandini A., Russo U., Uytterhoeven M.G. and Zanchini C. (1995) J. Chem. Soc. Dalton Trans. 6, 963-974.

[41]Cecconi F., Ghilardi C.A., Midollini S. and Orlandini A. (1987) J. Chem. Soc. Dalton Trans., 4, 831-835.

[42]Steigerwald M.L., Siegrist T., Gyotgy E.M., Hessen B., Kwon Y.U. and Tanzler S.M. (1994) Inorg. Chem. 33(15), 33893395.

[43]Cecconi F., Ghilardi C.A., Midollini S., Orlandini A. and Bencini A. (1996) J. Chem. Soc. Dalton Trans. 24, 3991-3994.

[44]Frenske D., Hachgenei J. and Ohmer J. (1985) Angew. Chem. Int. Ed. Engl. 24(8), 706-709.

[45]Cecconi F., Cecconi F., Ghilardi C.A., Midollini S., Orlandini A., Zanello P., Cinquantini A., Bencini A., Uytterhoeven M. G. and Giorgi G. (1995) J. Chem. Soc. Dalton Trans., 23, 38813889.

[46]Steigerwald M.L., Siegrist T. and Stuczynski S.M. (1991) Inorg. Chem., 30(26), 4940-4945.

[47]Frenske D., Hachgenei J. and Ohmer J. (1985) Angew. Chem. Int. Ed. Engl. 24(11), 993-995.

[48]Brennan J.G., Siegrist T., Stuczynski S.M., Steigerwald M.L. (1990) J. Am. Chem. Soc. 112 (25), 9233-9236.

[49]Hoffmann R. (1963) J. Chem. Phys. 39(6), 1397-1412.

[50]Hoffmann R. and Limpscomb W.N. (1962) J. Chem. Phys. 36, 2179-2189.

[51]Hoffmann R. and Limpscomb W.N. (1962) J. Chem. Phys. 37, 2872-2883.

[52]Mealli C. and Proserpio D. (1990) J. Chem. Educ. 67, 399402.

[53]Elian M. and Hoffmann R. (1975) Inorg. Chem. 14, 10581076. 